\title{
Blended Instruction in Online Learning Environments
}

\author{
Eunjoo $\mathrm{Oh}^{1}$ \\ ${ }^{1}$ Professor, Department of Liberal Arts, Kyungil University, Korea, eohl@ hanmail.net
}

\begin{abstract}
This paper examined how students perceive and evaluate online instruction. Mainly, it focused on students' satisfaction on using online instruction and their most preferred mode of presentation of instructional contents. The research participants consist of 206 freshmen from the 2020 academic year, of which 120 took the class in the first semester and 86 in the second semester. The data was collected online within the two semesters and the results were compared to examine whether there were any differences in their answers. The survey results were analyzed with SPSS 26 using technical methods and a T-test was conducted to find out whether there were any differences in their answers based on the semester. Open-ended questions were analyzed using text analysis to find the themes, focusing on the research questions. The data analysis results showed that the students seem to be satisfied with the online classes they took. In the first semester survey, students answered they do not want to take online classes anymore. However, in the second semester, more than half of the 48 students wanted to take classes online while 33 still wanted face-to-face classes. The respondents are currently taking online classes because of social conditions. If the situation improves, they want face-to-face classes to allow them to communicate with their colleagues and professors. Since they are freshmen, they wanted to experience campus life and socialize with their peers on campus. Based on the study results, instructional strategies and activities were suggested.
\end{abstract}

Keywords: Online Instruction, Blended Instruction, Evaluation, Instructional Design

\section{Introduction}

\subsection{Background}

The current society experiences unexpected changes every day. Most of the social areas had to stop working for a while and have been forced to adopt the changes of the systems to restart in a way to secure the safety of the society. People wear masks and avoid public gatherings. Social experts expect that this kind of pendulum keeps continuing to persist for a while. In terms of educational environmental aspects, the Covid 19 has already postponed the school opening three times and schools had to implement alternative delivery methods due to the sudden changes. All the academic institutions had to open minimally until the ways are explored and set up to manage the institutions safely. The institutions also had to implement online or blended instructional methods without having full preparations. When pandemics occurred in the first place, there was not any set of agenda about the education systems and presumed that society will resume to a normal situation soon. However, it is not certain how long this kind of situation continues and what will be the best solutions for keeping the shape of normal life. Therefore, education systems should prepare the schools to be ready for the changes by developing diverse ways of instruction in a way to keep the social distance[1].

Online instruction has been used as an alternative instructional mode for a long time and it will be one of the best options in the current situation. Although it offers many advantages, it also has issues such as isolation of learners and lack of communication among teachers and students. Considering these

Received: August 29, 2020; $1^{\text {st }}$ Review Result: October 14, 2020; $2^{\text {nd }}$ Review Result: November 30, 2020 Accepted: December 28, 2020 
disadvantages, previous studies suggested blended instruction, which is a mixture of online and offline classes instead of delivering the entire class online. However, today, blended instruction may not be an option. Therefore, it is better to find solutions for overcoming the disadvantages of online learning. This study attempted to find the best practices of online instruction by examining the students' perceptions and evaluation of online classes and find ways to effectively design the delivery of instruction.

\subsection{Research Questions}

The purposes of this study were to find out how students perceive and evaluate online instruction and propose the design of blended instructional strategies in online learning environments based on the study results. To achieve the study purposes, four research questions were proposed as follows.

(1) What is the student's satisfaction with online instruction?

(2) How do students perceive online instruction?

(3) What is the most preferred content delivery format in online instruction?

(4) How do students evaluate online instruction?

\section{Literature Review}

Social circumstances have changed unexpectedly where most educational organizations and its clients (or students) need to adjust themselves to the sudden changes. It is not a simple job for both educators and students to change the instructional mode and apply it to the normal curriculum. There has been a lot of confusion in delivering and taking classes during the semester. Most schools had to change the instructional delivery mode from classroom to online without having any full validated preparations[2]. The advantage of online education is that it is suitable for repetitive learning. It also provides a learning program appropriate to the learner's level and makes an effective curriculum possible for self-directed learning[3]. However, studies also revealed disadvantages that students feel isolated from the instructors and students in online learning and the quality of learning is not ensured. To be successful in online instruction, it was suggested to overcome such disadvantages in some ways[4].

Based on previous studies, blended learning is known to be an effective way to improve pedagogy and increase accessibility. It provides students with the flexibility to offer various learning situations and expand access to peers and instructors as well. Blended is also cost-effective in the sense that provides learning opportunities to a wide range of learners in a short period[5]. Besides, blended learning is an easy way to accommodate changes in education environments because it allows learners to gradually transition from traditional classroom instruction to online instruction. Blended learning can implement a learning strategy that can be more learner-centered[6]. No learning method or strategy can satisfy learners, but blended learning provides an opportunity to interact with learning content and goals in various and appropriate ways while respecting the diverse learners' styles as much as possible[7].

Blended learning goes beyond the dimension of the physical combination of online education and offline education. It is more of an approach that takes advantage of all the educational strategies that have been used so far to improve the learning performance and establish effective learning environments to respond to changes in the social environments[8].

In practice, blended learning was mostly applied in two types. It is used to supplement face-to-face activities using technology in offline classrooms or on-campus PC labs or using offline classroom classes and online activities after school[9]. According to[10], blended instruction can be adopted as an ideal learning system in language learning environments by reinforcing the two socio-cultural mechanisms of peer collation. In the classroom, learners work on a task as a team to help each other while in online learning environments, learners can work individually to accommodate and modify their own learning. There are many previous studies[10][11] that present good practices of blended instruction. 


\section{Research Design}

\subsection{Research Participants}

The research participants were 206 freshmen who took the online classes in the academic year of 2020. Among the total number of 206 participants, 120 took the class in the first semester and 86 in the second semester. The data was collected online for two semesters and the results were compared to examine whether there were any differences in their answers.

\subsection{Class Design}

There are four classes where each semester offered two different online classes. One was the theorybased class, and the other was the project-based class. The online classes, through the Everec program, were developed and facilitated by the researcher. The same classes were taught in two semesters but with different groups of students. The instructor videotaped the slideshow lessons embedded with the voice but not with the face of the instructors. The four online classes were delivered in a non-real-time method and students were given one week to finish one lesson. A survey was conducted after the semester.

\subsection{Research Methods}

A survey method was used to collect the data. Two online survey instruments (survey A and survey B) used. Survey A, created by the College E-learning Center (KOCW) was revised by the researcher according to the research purposes and was used in the first semester. It consists of one multiple choice question asking about the preferred mode of content presentation method, and 20 questions evaluated using a 5-point Likert scale. It asks about the quality of contents, design of contents, facilitation of learning support, system management, and satisfaction on the online class. In the second semester, survey B was revised by the researcher based on the results of survey A and used to collect the data. Unnecessary questions from survey A were erased while open-ended questions were added to survey B. Survey B consists of 10 questions, which are also evaluated using the same Likert scale, and 3 openended questions on the advantages and disadvantages of online instruction, and their preferred instructional mode for the next semester.

[Table 1] Research Instruments

\begin{tabular}{|c|c|}
\hline Semester & Questions \\
\hline $\begin{array}{c}\text { 1st semester } \\
\text { Survey A }\end{array}$ & One multiple choice question, 20 (5 Likert scale questions) \\
\hline $\begin{array}{c}\text { 2nd semester } \\
\text { Survey B }\end{array}$ & $12(105$ Likert scale questions, 3 open-ended questions) \\
\hline
\end{tabular}

\subsection{Data Analysis}

The data was collected online after the semester and they were analyzed using SPSS 26. Survey instruments examined the students' perceptions and satisfaction with online learning. The survey results were analyzed using technical methods and a T-test was conducted to find out whether there were any differences in their answers based on the semester. Open-ended questions were analyzed using text analysis to find the themes, focusing on the research questions. 


\section{Findings}

\subsection{Students' Satisfaction with Online Instruction}

To compare students' satisfaction with online instruction, three questions (\#1, \#18, \#12) were analyzed for both semesters. When analyzing the data, students' satisfaction with the online classes appeared to be the same with an average of 3.74. According to the data analysis, the students seem to be satisfied with the online classes that they took.

[Table 2] Students' Satisfaction with Online Instruction

\begin{tabular}{|c|c|c|c|c|}
\hline Survey & Semester & Question & $\mathrm{M}$ & S.D \\
\hline $\mathrm{A}$ & First Semester & \multirow{2}{*}{$\begin{array}{c}\text { Satisfaction with } \\
\text { online classes }\end{array}$} & 3.74 & 0.98 \\
\cline { 1 - 2 } $\mathrm{B}$ & Second Semester & 3.74 & 1.06 \\
\hline
\end{tabular}

The results of the evaluation on survey A yielded an average of $2.86(\mathrm{SD}=1.45)$, which also stated that the students did not want to take online classes on the next semester. In the second semester, the responses were different. The open-ended questions in survey B were given to find out more details about the students' satisfaction during the second semester. The results showed that 48 students will still take classes online while 33 preferred to take classes face-to-face. Interestingly, three students answered that they do not like the blended classes because it does not help them understand the study contents but confuse them only. It appeared that these students preferred either full online classes or offline classes.

Most of the students preferred online classes because they were already familiar with the systems used and its environments. It was also convenient for them in various ways. On the other hand, those who preferred to take the face-to-face-classes classes said that they would like to experience the campus life, socialize with other students, and communicate with the professors directly. Besides, they find the online classes too boring and some classes have low quality. Students' detailed responses are shown in [Table 3].

[Table 3] Students' Preferences about Instructional Mode for Next Semester

\begin{tabular}{|c|c|c|}
\hline $\begin{array}{c}\text { Preferred } \\
\text { Online } \\
\text { class }\end{array}$ & $\begin{array}{c}\text { "I do not feel much discomfort about online classes. I hope that online classes will be } \\
\text { held next semester because there is a big advantage that I can take video classes again." } \\
\text { "Classes that require practice are conducted face-to-face, but theories and team tasks } \\
\text { are sufficient for video or zoom, and they can be used efficiently by doing so." }\end{array}$ \\
$\begin{array}{c}\text { "I hope the class will proceed according to the progress of the Covid 19 like this year. } \\
\text { The most important thing is to be careful without getting a corona, so I think we should } \\
\text { proceed non-face-to-face except for departments with practice like now." }\end{array}$ \\
$\begin{array}{c}\text { Preferred } \\
\text { offline } \\
\text { class }\end{array}$ \\
$\begin{array}{c}\text { "In fact, the quality of online classes cannot be matched by the quality of face-to-face } \\
\text { classes, and we strongly hope for face-to-face classes, not just one or two }\end{array}$ \\
$\begin{array}{c}\text { uncomfortable things. Although there is nothing we can do about the Corona Covid 19, } \\
\text { we want to take both theoretical and face-to-face classes. They both have different }\end{array}$ \\
$\begin{array}{c}\text { strengths, so I thought it would be nice to have a lot of review materials during face-to- } \\
\text { face classes." }\end{array}$ \\
$\begin{array}{c}\text { "I have done many online classes and I want to take classes in the classroom because I } \\
\text { got closer to my classmates." }\end{array}$ \\
$\begin{array}{c}\text { Opinion } \\
\text { Blended } \\
\text { instruction }\end{array}$
\end{tabular}




\subsection{Students' Perceptions of Online Instruction}

The responses on the three open-ended questions in survey B were analyzed. In the question on the advantages of online instruction, 56 students responded that efficient time management is the best part of online learning. They answered that they can have personal time for their hobbies and enough time to spend on self-development. They also enjoy taking classes anytime, anywhere, saving them the time for commuting while providing a big advantage on learning management. Of the answers, 10 said that they can save the commute time, and 5 said that they can control their learning speed because they could replay the video lectures until they fully understand the contents.

[Table 4] Advantages of Online Instruction

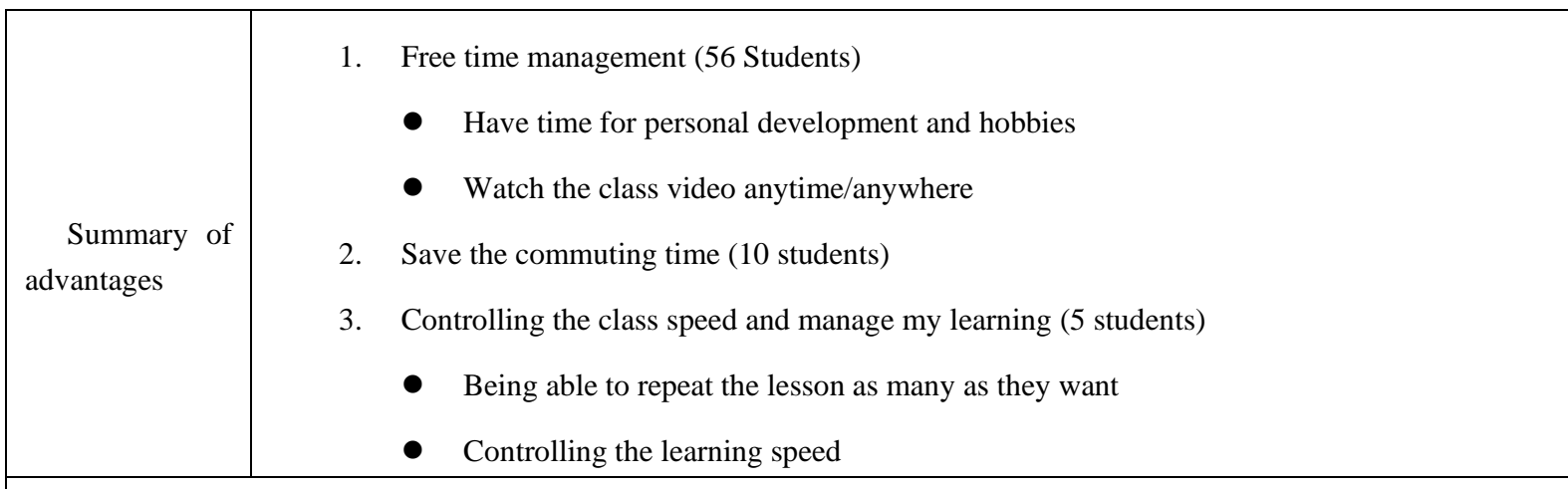

"It used to take almost two hours to commute from home to school, but I liked it because there was no such hassle. Because unnecessary travel time is shortened and classes can be taken autonomously, time can be used efficiently. In short, it is also good to work part-time on weekdays.

"As a person who commutes to school and does not live in a dormitory it takes 6 hours to go back and forth to and from school. However, if I take an online class, I can save my precious 6 hours and above all, I think the biggest advantage is that I can save transportation costs."

"I can divide time on my own and make room to study or exercise at regular times. I had a lot of time left, so I was able to spend time in a frugal way, such as exercising, reading, hobbies, and so on that time."

"I think it is good to be able to plan efficiently and take classes regularly when managing time. In the classroom, when the professor's words are not communicated, they record, but sometimes the classroom rings, and sometimes they think it is inappropriate to record, but they can watch the video again through online lectures, and it's not a burden to take notes personally."

"Unlike classroom classes, online classes have the advantage of being available anytime, anywhere. I also felt the advantage of being able to take classroom classes only at a fixed time, but being able to look back and learn things that I don't understand through online classes."

"I think the biggest advantage is that you can check what you did not know or what you don't understand by listening to the lecture again."

"I felt a great advantage in terms of time because I could take classes directly on my computer or tablet without having to go to school or leave school."

Regarding the disadvantages, most of the students pointed out the lack of communication as many previous studies revealed. There were 37 students who responded that it is difficult to get immediate feedback from the professors and communicate with other students, 18 pointed out that it is hard to concentrate on the online class compared to the face-to-face class, and 4 mentioned that time management skills are required to be on the right track. Furthermore, overloaded homework is one of the difficulties that the students experienced in online learning. The detailed responses are presented in [Table 5] below. 
[Table 5] Disadvantages of Online Instruction

\begin{tabular}{|c|c|}
\hline $\begin{array}{l}\text { Summary of } \\
\text { disadvantages }\end{array}$ & $\begin{array}{l}\text { 1. Difficult to communicate with colleagues or professors (47 students) } \\
\text { 2. Hard to concentrate. ( } 18 \text { students) } \\
\text { 3. Too many assignments. (11 students) } \\
\text { 4. Difficult to manage the time ( } 4 \text { students) }\end{array}$ \\
\hline \multicolumn{2}{|c|}{$\begin{array}{l}\text { "It is a little difficult to contact you personally by e-mail or contact you personally when you can't listen to the } \\
\text { class properly or when you have a question from the professor." }\end{array}$} \\
\hline \multicolumn{2}{|c|}{ "I am losing my interest and concentration on online classes as time goes by/" } \\
\hline \multicolumn{2}{|c|}{$\begin{array}{l}\text { "It was okay until the first semester to manage classes and assignments by myself, not the pressure of the } \\
\text { environment, but I felt a little tired after the second semester. That is why I couldn't manage my time well." }\end{array}$} \\
\hline \multicolumn{2}{|c|}{$\begin{array}{l}\text { "I have to do my attendance assignments every week, so I have a hard time and listen to lectures for a long } \\
\text { time. I am bored because I do not have any communication with my professor or students." }\end{array}$} \\
\hline $\begin{array}{l}\text { "I take thr } \\
\text { time to do }\end{array}$ & es a day and finish the assignment in three days, but if the video is long or short, I don't have \\
\hline
\end{tabular}

\subsection{Preferred Content Presentation Mode in Online Instruction}

When analyzing the questions regarding the content presentation in online education, students preferred non-real-time online instruction over real-time online instruction. Out of 120 respondents, 111 students (92\%) responded to "prefer non-real-time online classes" and only 9 students (8\%) answered to "prefer real-time instruction using Zoom". On non-real-time instructional mode, 92 (76.7\%) students preferred a voice-over PowerPoint presentation and 17 (4.2\%) preferred a class video with the instructor's face. They did not like an instructional video which contains only a PowerPoint.

[Table 6] Preferred Ways of Online Class Presentation Type

\begin{tabular}{|c|c|c|c|c|}
\hline & $\begin{array}{c}\text { Real-time instruction } \\
\text { (Zoom) } \\
9(8 \%)\end{array}$ & \multicolumn{3}{|c|}{$\begin{array}{c}\text { Non-real time instruction } \\
\text { (PowerPoint based video) } \\
111(92 \%)\end{array}$} \\
\hline $\begin{array}{c}\text { Presentation } \\
\text { Type }\end{array}$ & Zoon with audio and video & PPT with instructor's face & PPT with Instructor's voice & PPT presentation only \\
\hline Frequency & $9(8 \%)$ & $17(14.2 \%)$ & $92(76.7 \%)$ & $2(1.7 \%)$ \\
\hline
\end{tabular}

\subsection{Comparing the Evaluation of Online Instruction in Two Semesters}

When comparing the student's evaluations on communication opportunities with professors and peers, the means for the evaluations were low for both semesters. Communication opportunities with the professor and peers in the first semester showed a mean of 3.38 and 3.45 in the second semester. There was not any statistical difference in their means when analyzed with the T-test.

[Table 7] Comparisons of Communication Opportunities with Professors and Peers

\begin{tabular}{|c|c|c|}
\hline Questions & $\begin{array}{c}\text { 1st semester } \\
\text { Mean (S.D) }\end{array}$ & $\begin{array}{c}\text { 2nd semester } \\
\text { Mean (S.D) }\end{array}$ \\
\hline Enough opportunities to communicate with the professors were given., & $3.49(1.15)$ & $3.35(1.04)$ \\
\hline
\end{tabular}


Enough opportunities to communicate with peers were given.

Total Means

\begin{tabular}{l|l}
$3.28(1.27)$ & $3.55(1.34)$ \\
\hline $3.38(1.21)$ & $3.45(1.19)$ \\
\hline
\end{tabular}

When analyzing the students' learning opportunities, it appeared that the students were given enough study materials $(\mathrm{M}=3.85, \mathrm{M}=4.01)$ for both semesters. They also responded that online instruction helps them understand study contents and study goals $(\mathrm{M}=3.55, \mathrm{M}=3.88)$, but the means were not high. In the case of the effectiveness of online instruction, they do not seem to agree that online instruction is more effective than classroom instruction $(\mathrm{M}=2.78, \mathrm{M}=3.01)$. When comparing the students' learning opportunities for two semesters, there were statistical differences in providing study materials and understand the online contents $(\mathrm{P}<0001$.), but there was not any statistical difference in their perceptions of the effectiveness of online instruction. Detailed information about learning opportunities is presented in [Table 8] and [Table 9].

[Table 8] Comparisons of Learning Opportunities for Two Semesters

\begin{tabular}{|l|c|c|}
\hline \multicolumn{1}{|c|}{ Questions } & $\begin{array}{c}\text { 1st semester } \\
\text { Mean(S.D) }\end{array}$ & $\begin{array}{c}\text { 2nd semester } \\
\text { Mean (S.D) }\end{array}$ \\
\hline Online instruction provides enough study materials. & $3.85(1.03)$ & $4.01(0.88)$ \\
\hline $\begin{array}{l}\text { Online instruction helps me understand the study contents and achieve } \\
\text { the study goals. }\end{array}$ & $3.55(1.15)$ & $3.88(0.91)$ \\
\hline $\begin{array}{l}\text { Online instruction provides more opportunities and time to study than } \\
\text { class instruction does. }\end{array}$ & $2.78(1.28)$ & $3.01(1.3)$ \\
\hline
\end{tabular}

[Table 9] T-Test for Learning Opportunities between Two Semesters

\begin{tabular}{|c|c|c|c|}
\hline Question & $\mathrm{t}$ & $\mathrm{F}$ & $\mathrm{P}$ \\
\hline Online instruction provides enough study materials. & 20.128 & 204 & 0.00 \\
\hline Online instruction helps me understand the study contents and achieve the study goals. & -3.113 & 204 & 0.00 \\
\hline
\end{tabular}

Regarding the online organization of online materials, they perceived that the quantity of class content was appropriate $(M=4.18, M=3.83)$, and online instruction was presented on time regularly. The contents were well organized with continuity $(\mathrm{M}=4.5 \mathrm{M}=4.2)$. However, when comparing the response by the semester, there was a statistical difference in their answers. The students evaluated the online instruction for the first semester better than the second semester $(\mathrm{P}<0.001)$.

[Table 10] Comparisons of class organizations for two semesters

\begin{tabular}{|c|c|c|}
\hline Questions & $\begin{array}{c}\text { First semester } \\
\text { Mean(S.D) }\end{array}$ & $\begin{array}{c}\text { Second semester } \\
\text { Mean (S.D) }\end{array}$ \\
\hline The quantity of online instruction was appropriate. & $4.18(0.83)$ & $3.83(1.01)$ \\
\hline $\begin{array}{c}\text { Online instruction was presented regularly on time and the content } \\
\text { format had unity and continuity. }\end{array}$ & $4.5(0.62)$ & $4.2(0.9)$ \\
\hline
\end{tabular}

[Table 11] T-Test for Class Organizations Between Two Semesters

\begin{tabular}{|c|c|c|c|}
\hline Question & t & F & P \\
\hline The quantity of online instruction was appropriate. & 4.47 & 204 & 0.00 \\
\hline $\begin{array}{c}\text { Online instruction was presented regularly on time and the content format had unity } \\
\text { and continuity. }\end{array}$ & 2.7 & 204 & 0.00 \\
\hline
\end{tabular}




\section{Conclusions and Implications}

\subsection{Conclusions}

This study examined how students perceive and evaluate online instruction. It also examined whether the students were satisfied with the online instruction that they took and the most preferred content presentation mode of instructional contents. Data were collected for two semesters and the results were compared. The results showed that according to the data analysis, the students seem to be satisfied with the online classes that they took. When asking whether they want to take classes online next semester, in the first semester, they did not want to take online classes anymore, but in the second semester, more than half of the 48 students want to take classes online the following semester. However, 33 students still wanted face-to-face classes the next semester. The respondents are currently taking online classes because of social conditions, but if the situation improves, they want face-to-face classes that allow them to communicate with their colleagues and professors. Since they are freshmen, they wanted to experience campus life and socialize with their peers.

Interestingly, students answered that they do not like the blended instruction because it does not help them understand the contents of the lesson clearly, instead, it confuses them. It appeared that the students preferred total online or offline classes. The significant advantages of online instruction mentioned by the students were; they have free time for personal development and hobbies, and abilities to control their learning speed and time. They could take classes whenever and wherever they need them and that it was convenient for them to repeat the classes. On the other hand, the students pointed out that a lack of communication with professors and peers was the disadvantage of online instruction. They also appealed that they easily lose their concentration because it is too boring to learn from the instructional videos.

Regarding the instructional mode, the students responded to prefer non-real-time online instruction to real-time online instruction. As a way of content presentation, the students preferred class video containing a PowerPoint presentation and the instructor's audio explanation. They did not like the class videos with the instructor's face or PowerPoint presentation only videos. The students evaluated that the online classes are well organized with continuity and unity with the appropriate content quantity and study material such as class notes and the extra class materials help them to understand the class contents better. However, they did not perceive that online instruction provides more opportunities to study nor help them to achieve the study goals with more study time than classroom instruction.

\subsection{Implications}

Online instruction is inevitable in current situations. According to the research results, in the current situation, blended instruction that combines online and offline instruction is not an option anymore. Instead blending diverse instructional components in online learning environments can be one of the solutions that adjust the current and future situation. Based on the previous literature, blended instruction is a combination of online and offline instruction. However, this study suggests that the definition of blended instruction should be changed in a way that expresses the practical classroom situation online. As this study shows, students do not want to mix online and offline classes, and social circumstances change abruptly. Therefore, rather than planning blended instruction, which is a combination of online and offline instruction, it is better to plan all classes online at the beginning of the semester until the social situation is stabilized. Therefore, a new definition and model for blended instruction should be established based on current practices. 


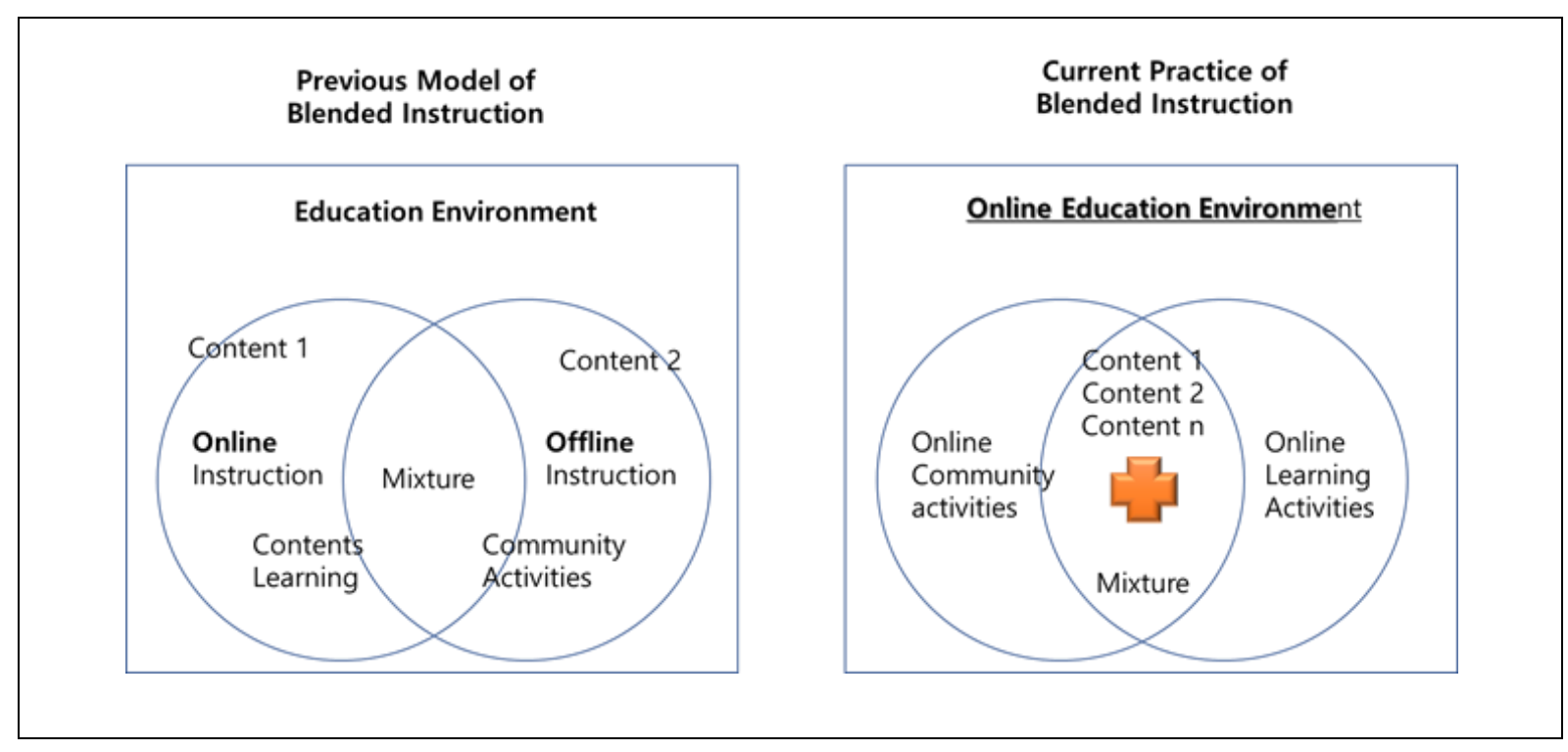

[Fig. 1] Blended Instruction Model for Previous and Current Situation

Since society keeps requiring social distancing, schools must prepare for delivering entire classes online at any time. Previous studies already discussed the disadvantages of online instruction and thus, instructional strategies can be designed to overcome the disadvantages by blending instructional strategies and activities in online learning environments. Using diverse technologies and developing activities can be one way to satisfy the students' needs.

The mixture of community activities and learning activities is with a typical way of blending activities in online learning environments as shown in [Table 12] below. Community activities include posting information, using a free communication board, real-time chatting, and discussions. Learning activities include lectures, real-time learning activities, evaluations, feedback, providing learning resources, and posting assignments.

[Table 12] Two types of Activities in Online Learning Environments

\begin{tabular}{|c|c|}
\hline Community Activities & Learning Activities \\
\hline & Lectures \\
Information Posting & Learning Activities \\
Free Communication Activities & Up-loading Learning Resources \\
Real-Time Chatting & Assignments and feedback \\
Discussions & Evaluations and feedback \\
& Real-Time Activities \\
\hline
\end{tabular}

To successfully utilize such activities in class, instructors must know how to use technologies such as community applications and learning applications. There are a variety of applications that can promote students' learning. When designing instruction, instructors have to combine their activities with appropriate technologies to make students actively engage in their learning. Even though there are many functions to communicate with students in the LMS, instructors merely upload the class videos and textbased study material. There are not many cases found that instructional design is included with learning activities according to the contents. The success of online instruction depends on how instructors combine instructional strategies with the class contents and technologies. This study found that learners do not want a traditional way of blended learning, which is a mixture of online and offline classes. Therefore, instructors put more effort into the best practices in the online learning environment and more studies should be done to find the best practices for combining community and learning activities. This study examined the small number of classes taught by the same instructor and thus, there are limitations in generalizing to explain the phenomenon of online classes. Therefore, more case studies should be 
conducted to examine the problems and find the solutions for the best educational practice in online learning environments.

\section{References}

[1] S. A. Park, A Study on the Development of Collaborative Knowledge Construction Procedural Model in Blended Learning, Hanyang University, Doctoral Dissertation, (2011)

[2] H. Y. Kim, Learning Achievement Analysis in Drawing Classes with Blended Learning, Korea Broadcasting Communication University, Doctoral Dissertation, (2016)

[3] T. E. Kim, Effectiveness of Blended Leaning Utilizing the Home Cyber Studies to the First Grade Math High School Students, Korea Teacher's University, Master's Thesis, (2011)

[4] A. R. Cho, The Necessity of Mathematical Classes Utilizing Smart Learning in Blended Learning Environment, Kyunghee University, Master's Thesis, (2016)

[5] S. Y. Yang, Moodle Based Blended Learning for English Learners, Korea Broadcasting and Communication University, Master's Thesis, (2019)

[7] A. R. Cho, The Necessity of Mathematical Classes Utilizing Smart Learning in Blended Learning Environment, Kyunghee University, Master's Thesis, (2014)

[8] H. M. Kim, J. Y. Kim, A Meta-analysis of English Education Researches Using Blended Learning and Flipped Learning, The Journal of Learner-Centered Curriculum and Instruction, (2019), Vol.19, No.21, pp.241-258

[9] W. S. Kim, Analysis of Student Satisfaction Survey on Computer Practice Subject by Applying Blended Learning, Journal of Korean Association of Information Education, (2015), Vol.19, No.3, pp.379-384.

[10] J. Y. Lee, The Development of University Students' L2 Listening Comprehension through Metacognitive Instruction with Peer Collaboration and Scaffolding in Blended Learning, Hankkok University of Foreign Studies, Master's Thesis, (2015)

[11] S.Y. Yoon, C. H. Lee, The perspectives and Effectiveness of Blended Learning in L2 Writing of Korean University Students, Multimedia-Assisted Language Learning, (2010), Vol.13, No.2, pp.177-204. 